\title{
Does Dual Training Make the World Go Round? Training Models in German Companies in China, India and Mexico
}

\author{
Matthias Pilz ${ }^{1}$ (D) Kristina Wiemann ${ }^{1}$
}

Received: 3 March 2020 / Accepted: 15 July 2020 / Published online: 30 July 2020

(C) The Author(s) 2020

\begin{abstract}
The transfer of dual training from Germany to other countries is widely debated. However, there is little, if any, academic research in this area. The present study addresses this research deficit and examines the training activities of German companies in China, India and Mexico. Data was collected in 86 manufacturing companies of differing sizes and producing different goods. The evaluation of a total of 149 interviews with training experts showed that both the local training system and the German system can serve as a model for companies' training. Hybrid forms combining local and German elements also exist. Even within a company, different parallel types of training can be identified. However, the orientation to local training practice is the dominant model in all three countries.
\end{abstract}

Keywords Apprenticeship training · Transfer of VET · In-company training • Mexico • India $\cdot$ China

\section{Introduction}

Dual training models are often discussed as a way of tackling both the skills shortage many countries face and youth unemployment (Zimmermann et al. 2013). In Germany and countries including Austria and Switzerland, such approaches are well established and have evolved over time, giving rise to the question of whether dual training models can also be transferred to other countries.

\section{Matthias Pilz}

matthias.pilz@uni-koeln.de

Kristina Wiemann

kristina.wiemann@uni-koeln.de

1 University of Cologne, Herbert-Lewin-Str. 2, 50931 Köln, Germany 
Many projects in different countries have sought to establish dual approaches to training, but a number of studies indicate that it has proved almost impossible to find examples of long-term successful transfer of dual models (Gonon 2014; Valiente and Scandurra 2017). However, there are no detailed academic findings on transfer (see below). Stockmann and Silvestrini (2012) explore the outcomes of international technical vocational education and training (TVET) projects as part of a meta-evaluation by the Deutsche Gesellschaft für Internationale Zusammenarbeit (GIZ). They conclude that most projects are modest pilot projects and are not sustainable but are based mostly on bilateral or multilateral cooperation arrangements and focus on state cooperation to tackle challenges including high youth unemployment and stagnating growth.

The study is based on the conceptual and theoretical assumption that transfer of dual training activities is most likely in the case of German companies and that dual training is part of the "baggage" that accompanies these activities when they are exported (Pilz and $\mathrm{Li}$ 2014). Most German companies have detailed knowledge of the organisation and advantages of the dual TVET model, and it is reasonable to assume that they are keen to establish it in their plants abroad too. Path dependency can therefore be assumed (Thelen 2004) and conceptualised through the link with the German parent company, facilitating orientation to the German model. However, the influence of the local environment is also important (Gessler 2017; Pilz and Li 2014) and may be central in orienting training activities more to the local context.

This process recognises different interests and puts the emphasis on transfer of the dual model of training per se rather than on analysis of its advantages and disadvantages. This is in no way to deny the existence of other valid forms of vocational education and training in other countries or, indeed, of weaknesses in the dual system in Germany. The focus on the dual system in the context of the transfer debate therefore particularly reflects the fact that over recent years, the debate surrounding this model of TVET has been particularly intense (Valiente and Scandurra 2017).

\section{The Research Question: Current Research and the Theoretical Basis}

Subsidiaries of German multinationals find themselves pulled in different directions, and the focus of this study is to investigate influences and outcomes. By contrast with other comparative TVET studies, this article will not take a top-down approach that foregrounds the state's role (Gonon 2014; Lewis 2007) but, rather, a bottom-up approach, foregrounding companies' training practice. Our approach to the research question is therefore an exploratory one, underpinned by the theoretical models needed to develop an analytical model. This approach is typical of areas that have so far not been extensively researched and cannot therefore easily be applied to the preparatory work for the study.

The article will consider the following research questions:

Which models of initial and continuing technical training can be identified in the foreign subsidiaries of German manufacturing companies?

a. Are these oriented mainly to the German model or the local context?

b. What other local solutions are there? 
This article therefore draws on the debate around international comparative TVET research into the transferability of (German) dual training structures (Davoine and Deitmer 2020; Gessler et al., 2019; Stockmann and Silvestrini 2012; Wiemann and Fuchs 2018). It aims to help broaden understanding of company training activities outside Germany and, more broadly, of development cooperation and TVET cooperation. The aim is not to take a normative approach that assumes that the ideal is maximum orientation to the German model or invests it with the nature of a role model but rather to use the German system as a role model to underpin a systematic comparison with local variants in the research regions identified in practice.

Studies by Aring (2014), Gessler (2017), Li et al. (2019), Pilz (2016b), Pilz and Li (2014) and Wiemann and Pilz (2020) take a similar approach, focusing on individual company stakeholders rather than the national level. These studies explore the extent to which German multinationals pursue dual training in their foreign subsidiaries and interpret the findings against the background of transferability to other countries of German TVET models. Their findings also demonstrate the significant influence of local environments. In a case study for the International Labour Organization (ILO), however, Aring (2014) notes a substantial German influence at Volkswagen, BMW and Siemens subsidiaries in North America, albeit with significant local adaptation. In a study on training at Mercedes Benz in Alabama, Gessler (2017) identifies successful transfer activities but notes that the local context produces significant deviations in implementation within individual plants. This may therefore, Gessler argues, be a case of transformation rather than transfer.

Given their case study design, the findings of Gessler (2017) and Aring (2014) are of limited general applicability, however. They are also based solely on multinational global players, which enjoy generous resources and often function as beacons and interesting case studies but are unlikely to be models for other companies, as Stockmann and Silvestrini (2012) note. The restricted database limits applicability of the findings, however, making it difficult to identify country- or sector-specific influences. Consideration of more companies with differing profiles could usefully supplement these findings.

Studies by Pilz (2016b) and Pilz and Li (2014) represent a good starting point, on which this study builds. They consider the training activities of German subsidiaries in China, India, Japan and the US in the context of the parent companies' globalisation strategies. The authors identify a marked orientation to the local context, except in Japan, but the limited sample size restricts the conclusions that can be drawn. The authors also take a national approach that does not consider in-country differences. The current study considers in detail German companies' differing training strategies at their foreign production plants.

For the purposes of this study, the complexity of Germany's vocational training system requires a detailed definition of a "dual" training model. Discussing the transferability of dual approaches, Gonon (2014) identifies seven criteria, including companies' fundamental willingness to provide training and the existence of vocational schools as a second learning location. However, these two criteria must be accompanied by other defining characteristics, argues Gonon (2014): a statutory framework for state-recognised qualifications that are embedded in the broader training and employment system; involvement of specialist expertise alongside experience-based learning; joint organisation of TVET by the state, the private sector, employers and unions; a 
holistic view of occupational profiles; and recognition of TVET as relevant to individuals' careers.

To reflect adequately the complexity and level of detail of the findings, the study makes use of a three-level model (Table 1). Three components underpin this model and the study of the complex individual dimensions of skills training within companies. First, targeted consideration of specific teaching and learning activities takes place at the micro-level, using the approach proposed by Billett (2001). Second, embedding in contextual factors and their influence is an important explanatory parameter (embedding in the national education system, Pilz 2016a) and using the sociocultural importance and regulations of the world of work as a framework for organising work at company level (Wolf 2017). Third, consideration is given to the particularity of managing a multinational company (Dowling, Festing and Engle 2008). The analysis focuses on the potential influence of the German parent company or local decisionmaking by the subsidiary.

The starting point for the study is the exploration of specific teaching and learning activities. It is based on the findings of Billett (e.g. 2001) on workplace learning, which serve as a focus for implementing teaching and learning activities. This focus enables actual local practice to be studied and, subsequently, compared with the ideal represented by the German model. To enable features to be analysed systematically, incompany training is broken down into key research categories (training objectives, content, methodological/pedagogical implementation, materials, and learning environment).

To enable us to investigate not just local training but also the framework within which it happens, we also consider how vocational training is managed in the focus regions. The concept of skills formation systems (Busemeyer and Trampusch 2012; Pilz 2016a, 2017) considers the political and socioeconomic institutions and other stakeholders involved in TVET and explores how training is organised and socially

Table 1 Multi-level concept with research categories

\begin{tabular}{|c|c|}
\hline Level & Research category \\
\hline $\begin{array}{l}\text { Macro-level } \\
\text { Institutional structures and economic, social and } \\
\quad \text { political framework }\end{array}$ & $\begin{array}{l}\text { Responsibility for training } \\
\text { Characteristics of local labour market } \\
\text { Connections with local (vocational) training system } \\
\text { Respect for TVET (socioculturally-determined) }\end{array}$ \\
\hline $\begin{array}{l}\text { Meso-level } \\
\text { Organisational and regulatory design of TVET }\end{array}$ & $\begin{array}{l}\text { Decision making and strategy development in } \\
\quad \text { multinational companies } \\
\text { Production-oriented training needs } \\
\text { Recruitment } \\
\text { Financing } \\
\text { Examinations/certification } \\
\text { Initial and continuing training staff } \\
\text { Content sequencing }\end{array}$ \\
\hline $\begin{array}{l}\text { Micro-level } \\
\text { Specific teaching/learning activities }\end{array}$ & $\begin{array}{l}\text { Training objectives } \\
\text { Content } \\
\text { Methodological/pedagogical implementation } \\
\text { Materials } \\
\text { Learning environment }\end{array}$ \\
\hline
\end{tabular}


managed in a country. This approach investigates the influence of differing stakeholders on training policy, direct financing, and financial participation. An initial distinction may be drawn between models in which the state has a major influence (state model) and in which companies are most influential (segmental model). When both state and companies have substantial influence, this constitutes a third (collective) model, while a liberal model is in place where both state and companies have only limited influence. This idealised model had been much criticised in the past, not least because of its rather simplistic assumptions (Ryan 2012; Lauder, Brown and Ashton 2017), but it can offer an initial approximation to specific structures and influencing factors.

In the context of implementing dual models of training, this gives rise to the question of the extent to which companies have any responsibility for training and are willing to pay for it. Companies are very sensitive to the costs involved in training, particularly in countries with no dual tradition: if expensively-trained employees subsequently leave the company or are 'poached' by other employers, this is a loss to the training company (Mohrenweiser, Zwick and Backes-Gellner 2019; Muehlemann and Wolter 2011). Financing of training is, therefore, a relevant research dimension.

Possible parallels with Germany's dual model of TVET of particular importance to the study are the scope for cooperation with vocational schools and the role such schools play in preparing trainees for the world of work: they partner with companies only where their provision is considered to be of adequate quality and supports skills development enabling trainees to be deployed within companies. From the company's perspective, major differences in quality and inadequate transparency result from a lack of standardisation in such areas as curricula, the design of final examinations, certification processes and the training of instructors (Pilz 2016a, 2017). This may give rise to a mismatch between companies and vocational schools, creating a structural obstacle to the implementation of dual approaches.

Alongside the framework created by the interaction between state management, the involvement of companies and the scope for cooperation with vocational schools, the role young people and their parents play in TVET is also relevant. Society's image of vocational training also affects the transferability of dual approaches: differentiation and separation between general and vocational training and the potential presence of a hierarchy of career paths mean that many countries without a culture of dual training attach low status to TVET (Pilz 2012, 2017). This kind of stratification (Allmendinger 1989) results in young people opting for academic training instead, making it difficult for companies to recruit and retain suitable candidates for demanding positions in production making dual training less attractive. If vocational training attracts only those school-leavers with no prospect of 'better' academic options, this serves as a brake on high-quality training and the necessary investment by companies unable to recruit suitable staff. This study therefore also includes both the macro-level sociocultural status of vocational training and the scope of companies to recruit.

Alongside these structural factors, other factors relevant to potential transfer activities within companies are what Wolf (2017) calls the "employment culture background to vocational training" - the interdependencies between the cultural importance and regulation of work that govern the success of any transfer. Wolf builds on the findings of 1960s industrial sociology to argue that production regimes in different countries develop differently and are not (primarily) driven by technological factors. For 
example, a company's degree of technological development and the way in which it organises work closely correlate with the skills needed by production workers and, therefore, also with training requirements. Technological development and work organisation are reflected in, inter alia, automation technology and digitally-networked production, the extent to which work processes are broken down in a Taylorite or holistic organisation, the presence of hierarchies, the allocation of roles and responsibilities, and the related shaping of cooperation and communication between employees. However, production methods abroad may also differ fundamentally from those in the parent company, so production-oriented requirements are an important part of this study. These differences do not necessarily mean a lower level of technological development but may have strategic origins. The current study, for example, takes a differential view of the value attached to subsidiaries in the overall company structure: they may be autonomous innovation locations with high demands of their production workers or they may be spin-offs whose role is to save money and bring down labour costs for predominantly manual activities as part of an 'extended workbench'. Wideranging dual training activities can actually over-qualify workers for this kind of strategy.

As well as this framework, which influences every company, multinational companies are also in a particular situation: the study assumes that a multinational represents a conflictual relationship between standardisation and localisation. By contrast with the concept for national TVET models set out above, standardisation in this context can be understood as equivalent influence on transfer options. Significant standardisation means global approaches to consistent Human Resources (HR) strategies, guidelines and instruments throughout the company. Limited standardisation, by contrast, foregrounds local development and implementation of such strategies and practices and is consistent with the local environment (Bartlett and Ghoshal 1989; Dickmann, MüllerCarmen and Kelliher 2008). Festing and Eidems' (2011) model based on Dowling et al. (2008) and Festing, Eidems and Royer (2007) provides important input into the theoretical and conceptual framework of this study: the authors foreground internal factors, adding significantly to the models already outlined in this section. Trends towards standardisation emanate from the multinational itself, while trends towards localisation are primarily local. This means that management of and cooperation in training decisions across a multinational company are relevant to the nature of the training it offers. The literature also demonstrates that the influence of local factors may vary considerable from country to country and is therefore difficult to define in any standard way.

The theoretical approaches outlined here were condensed into a multi-level concept and translated into the following research categories for the empirical study (Table 1). The focus was on analysing specific teaching/learning activities and the framework governing them.

\section{Methodology}

The study is based on a qualitative study in Greater Shanghai (China), the industrial triangle of Mumbai, Pune and Bangalore (India), and the industrial belt in the central highlands of Mexico (Guadalajara, Querétaro, Estado de México, Mexico City and 
Puebla). These urban centres attract direct investment by German companies and have long been home to manufacturing operations. The selection of these countries from among those in which Germany most frequently makes direct investment was based on the 'most different approach' model (Przeworski and Teune 1970; Seawright and Gerring 2008). The regions contrast in many ways, including their colonial past, their state planning systems and economic liberalisation strategy, their teaching/learning practices, and other sociocultural aspects. Their vocational training systems are also based on different 'skills formation systems' (Pilz 2017) or 'training cultures' (Pilz 2009). For example, TVET structures in the three countries represent different 'skill formation systems' (Busemeyer and Trampusch 2012): the Chinese system is largely state-dominated, whereas India and Mexico have individualised management mechanisms with little influence from either the state or business. There are marked sociocultural differences between the latter two countries, and the Mexican government has put its own model of dual TVET in place with the aim of integrating business more closely in responsibility for training (for further detail, see Pilz 2017).

Data was collected in 86 manufacturing companies. Many companies were contacted locally, but only some were willing to be interviewed, so the sample reflected willingness to participate. As well as major multinational companies (global players), the sample also included smaller multinationals. In sectoral terms, the main focus was on mechanical and plant engineering, the automotive and supply sector, electronics and chemicals; it is in these sectors that the level of German investment abroad is highest (Deutsche Bundesbank 2019), making them particularly relevant. To ensure potential German influence, only companies wholly or substantially in German ownership were included. Most companies manufacture for both the domestic and the international market, and their products and production processes comply with the quality standards of the German parent company. Our sampling was unable to reflect the extent to which subsidiaries were independent of the group HQ in Germany in setting their training strategy: this was determined only during the survey itself and so represents one of the findings.

The main data collection method was the expert interview (Meuser and Nagel 2009). This qualitative method was chosen to elicit in-depth explanations of the implementation, purpose and results of in-company initial and continuing training activities. 149 interviews were conducted, in particular with HR managers, heads of training and plant managers in the subsidiaries of German manufacturing companies. The researchers also visited training institutions and analysed documents, e.g. training materials. In all three countries, interviews were also conducted with experts from public and private sector TVET institutions to enable the broader context to be assessed.

Using the theoretical approach (Table 1), a system of categories was devised to form the basis for the interview guidelines. The individual categories were systematically translated into questions and compiled into a coherent guiding framework. Some of the questions were fleshed out with specific examples and practice-related follow-up questions to ensure sufficient contextualisation for the survey. All interviews were recorded, transcribed and triangulated using content analysis methods and crossreferenced (Kuckartz 2014).

As part of data collection and evaluation, the researchers devised country-specific models of skills training, compared them with the German dual model, and compared the models with each other. In line with a 'problem approach' (Holmes 1958), they 
consciously avoided a wide-ranging descriptive macro-comparison of individual TVET systems, focusing instead on specific problem aspects derived from the findings. The creation of a typology (Kuckartz 2014, pp. 103ff.) was an inductive process based on the material. On the basis of summaries, clusters were derived and criteria devised for allocation to groups.

\section{Findings}

All three countries have significant demand for specialists trained for complex roles, which local labour markets and existing training mechanisms cannot meet. Dual training approaches are therefore relevant to resolving this problem. Transfer activities could be identified in all three countries, but so too could locally-oriented training activities. There was also evidence of various hybrid solutions strongly influenced by the local circumstances. As explained above, local characteristics and influences vary from country to country. Space constraints rule out a detailed description here of the local training and employment situation in the three countries, but individual local aspects are integrated into the discussion. For detailed information about the specific situation in each country, see for example, Li et al. 2019, Wessels and Pilz 2018, and Wiemann 2020a; 2020b).

The models identified here have been grouped together and are presented below and illustrated with quotes from interviewees. The two ends of the spectrum (solely local orientation and close alignment with the German dual model) are broadly similar across regions, so no regional distinction is made. Particularly interesting are the hybrid models, which differ substantially between countries.

\section{Models Oriented to the Local Training Framework}

In all three countries, the study identified training models based closely on the local training framework. As explained above, it was not possible to describe in detail the full set of local influences on and characteristics of training in all three countries. Instead, the study discusses the extent and degree of deviation from the German model and provides an integrative analysis of local alternatives. Although the training models based closely on the local training framework demonstrate regional characteristics, in particular in the extent to which they are based on national TVET systems, they all also demonstrate separation between activity profiles with low and high levels of complexity.

For activity profiles with a low level of complexity ('operator' or 'worker'), very restricted and occupation-specific initial training is provided. This is confined to individual stages in work processes and geared directly to workplace requirements. The workplace is the only learning location. There is virtually no formal provision; instead, content and time are structured on an ad hoc basis, reflecting the needs of the manufacturing process. Methodological and pedagogical design tends not to be coordinated and is overseen by a more experienced employee. Employees receiving this initial training start by observing processes, which they then carry out themselves. In some cases, to assist learning, greater emphasis is placed on verbalising processes, and individual activities have detailed, but easily-understandable process descriptions, 
which function as learning materials. It cannot be assumed that the workers carrying out these activities have good literacy, so materials are based mostly on photos and graphics, particularly for assembly activities. The HR representative of an automotive supply company summarised the process:

\section{"Just show them how to do this and then let them try. If it is not correct, then correct them. We just follow work in WI or 'Work Instructions'." (Interview C28) $)^{1}$}

For specialist activities in, for example, maintenance/repairs or quality control, workers are often 'poached' by other companies once they have several years' relevant experience and, in some cases, an academic qualification. In such cases, following the general initial training, they also undergo specific 'on-the-job training' (OJT) in tandem with experienced colleagues. The focus of OJT is on specific positions and activity profiles, and these activities are often topped-up with external modular training provision when the need for initial training cannot be met within the company or particular certification is required (e.g. for welding). In particular for activities in maintenance and repairs, machine manufacturers normally tailor their training provision closely to their customers, and companies make use of this. Skills matrices chart the demands of individual roles and how far each employee has been trained, enabling them to be allocated to a position, as well as demonstrating what support they need and whether they can provide training to other workers.

Overall, these two models based on local training are largely unrelated to the German dual training model. Rather, they are similar to local training practice, as shown in relevant comparative studies of local companies in China ( $\mathrm{Li}$ et al. 2019), India (Pilz 2016c) and Mexico (Wiemann 2018). Initial and continuing training activities are not geared to comprehensive, practical skills enabling the individual to acquire expert status: they focus instead on the company's own skills needs. Most production processes are geared to manual or low-skilled activities. Rapid familiarisation is a low-cost way for companies to meet short-term staffing needs. Learning processes are embedded in working processes but are not based on an alternating model of workplace and school learning. Because there are no standards, either for training or for instruction, learning processes are opportunistic and focus on securing benefit as rapidly as possible. The process can be shortened if experienced workers can be recruited for higher-level roles. Certificates are not awarded because there is no cooperation between company and state or other stakeholders.

\section{Training Models Oriented to the German Dual Model}

In all three countries, the study identified a training model with clear similarities to the German dual TVET model. In terms of content, this is reflected, for example, in adaptation of German curricula, arrangements for training instructors and certification. The focus is on employability in a training occupation and not, therefore, restricted to individual companies' requirements. The focus on wide-ranging and non-fragmented work processes gives the trainee a holistic overview of the individual components of production. During training phases in the teaching workshops, which are often available, trainees initially acquire basic

\footnotetext{
$\overline{{ }^{1} \text { The coding indicates country }(\mathrm{C}}=$ China, $\mathrm{I}=$ India, $\mathrm{M}=$ Mexico $)$
} 
skills, such as filing, grinding and turning. They then work increasingly independently, making the trainer a kind of tutor. Following basic training, trainees acquire the necessary support skills to prepare, complete and check their work.

Considerable emphasis is placed on developing self- and social competences, as this representative of a Chinese company explained:

“The other way is, like we say, 'open eyes' - how to work with others, how to work with Westerners, how to work with precision, how to gather experience life experience, work experience, being with people experience." (Interview C7)

Many of the companies surveyed regard wide-ranging and complex training as a major investment. The training manager in a major Indian automotive company explained that his company used complex training to remedy the narrowly-focused vocational focus of India's school and university system:

\begin{abstract}
"After completing three years, they have been through all the departments and they know each and every thing. They know the entire product cycle and they have a better idea than anyone else. They have a whole view - a helicopter view. It is very easy for them to suggest solutions for any problems or issues. They can identify the root cause of any problem easily." (Interview I10)
\end{abstract}

However, some companies do not run their own training activities but cooperate instead with training providers, such as major German companies running their own training centres, or buy training run by German Chambers of Commerce Abroad.

Most companies, though, need only a small proportion of their total workforce to have complex specialist training requiring a dual approach. Such dual approaches are therefore the norm especially in large companies and those having special productionrelated requirements for technical specialists. Training practice includes a wide range of initial and continuing training activities oriented to individual groups of activities.

All interviewees also noted that it is neither desirable nor possible to replicate Germany's dual specialist training model. Chinese framework curricula, for example, require adaptation, and many Indian companies prefer to provide training themselves rather than cooperate with low-quality schools. Largely unstandardized training in companies is, therefore, a key area of difference from the German TVET model, particularly in terms of companies' training plans and training for trainers/instructors.

\title{
Training Hybrids in the Three Countries
}

Companies that develop their own approaches rather than following the local context or the German parent company's model are particularly interesting. These companies base their training strategies closely on their own needs and make use of the specifics of the local framework, giving rise to a strong local character and widely-differing practices. This article therefore considers these hybrids on a country basis. ${ }^{2}$

\footnotetext{
$\overline{{ }^{2} \text { Further hybrids were identified, }}$ some of which were similar to those described here. In presenting the findings, we shall therefore present just one hybrid per country.
} 


\section{Training Hybrid in China}

China has an established system of vocational schools, which may cooperate with companies (Hao 2012). To provide initial training for specialists, companies cooperate with schools to recruit and employ apprentices; the specific arrangements are based on agreements between company and school. Trainees commonly spend their first two years in full-time school-based training, moving to the company for the final year. The wholly company-based learning environment described under locally-oriented models is therefore supplemented with a school-based component. In some cases, there are practical blocks of several weeks interspersed with school-based blocks. During schoolbased blocks, content focuses primarily on theory, with very little reference to specific company situations. Companies generally have little influence over training content laid down centrally by the Ministry of Education (MoE). In relation to methodological and pedagogical aspects, most teaching is face-to-face and teacher-centred, with great emphasis on learning by rote and too little on independent working and problemsolving. The German training manager of an automotive manufacturer saw considerable room for improvement compared with the teaching in German vocational schools:

\section{"But the whole school system is based on rote learning and examinations; there's} no cross-cutting knowledge." (Interview C39)

Some companies therefore have their own 'cooperation classes', accessed only by trainees who will subsequently be employed within the company. Some of these classes are equipped with the company's own machinery, so trainees receive optimal preparation for working in the company. Specialist continuing training (sometimes in Germany) is also available through these companies. However, the state-prescribed curricula are not open to influence, even in the context of such close cooperation. Support focuses primarily on increasing the amount of practical training provided in vocational schools. If trainees are employed following their apprenticeship, the transition is mostly seamless, as they are able to be employed directly in the area of their final in-company training block. On completion of their apprenticeship, they take the school's final examination and receive their qualifications. There is no examination in the training company. As the German manager of a chemical plant explained:

"There is no extra certificate to say they've covered it all. And we protect ourselves that way, because they could otherwise take that certificate to other employers. So, they don't get a certificate from us; all they get is the apprenticeship contract." (Interview C44)

Many of those surveyed indicated that the German dual TVET model is a kind of role model for their own activities, even though it applies to only a relatively small proportion of employees. However, interviewees also noted that because the framework is different, the German system was not a blueprint but rather an orientation to some fundamental ideas, which are adapted as required. Companies therefore prefer to implement practical training components and involve companies as well as schools. The combination of modes and locations enables trainees to acquire broader specialist knowledge than is required by a single company. However, the extent to which this is 
then linked with in-company phases is limited. Another fundamental difference from the German dual model lies in the cooperation between the private sector and the state: trainees sign a contract solely with the school, so this is not a tripartite arrangement, as in Germany (where employers'bodies and unions are also involved), but a bilateral contractual relationship between school and student.

\section{Training Hybrid in Mexico}

A similar approach is evident in Mexico. Here, too, companies have cooperation arrangements with vocational schools to train experts and focus solely on specialists, using the scope of the Mexican model of dual vocational training introduced relatively recently, in 2013, as part of a pilot project. The overarching objective of this initiative, which is supported by the German government, is to make Mexico's vocational training more practical and needs-oriented. On completion of the pilot project in 2015 (involving 6 courses and 11 states), the dual model officially become part of secondary phase II. At the time the research for this study was completed, there was little standardisation in the design of dual training courses.

Students frequently spend the first of their three-year training solely within a school. After the second semester, those with good marks can be put forward by their teachers to work in companies participating in the programme. The next two years are spent solely within companies, with trainees moving around different jobs. They remain trainees, so companies do not have to pay them a salary or training allowance, but can apply for a state bursary (Wiemann 2020a, pp. 80ff; 2020b).

By contrast with locally-oriented training, this model has parallels with Germany's dual model. For example, some of the training content has been translated from German or adopted from German teaching materials, such as keeping a work-log. Learning involves alternation between modes, with specialist knowledge acquired in school-based blocks supplemented with practical in-company learning. However, greater weight is placed on practical experience than on academic learning. The low level of standardisation of company training is therefore a major difference from the German model, with further differences in company curricula and training for instructors. The German head of a training centre explained:

"We have begun to break down the German training framework and apply it in chunks to the situation here in Mexico. We started by asking what happens in Germany and what has to happen in Mexico." (Interview M9)

There is also cooperation between the private sector and the state. One example is the training contract that trainees sign directly with the state and not, as in China, for example, with the vocational school. Another example is the involvement of employers and unions in curriculum development and examination arrangements.

\section{Training Hybrid in India}

While the hybrids in China and Mexico show some similarity to the German model, the Indian hybrid is least like the German model. 
The companies surveyed pursue a multi-skilling approach that means workers can be deployed anywhere. New employees are therefore given initial training in a range of roles in the production process and can then be moved (almost) anywhere in the company. Training lasts between 18 months and two years, but trainees can be productive at individual workstations within a few weeks or months, depending on role complexity. The transition from initial training to regular employment is therefore fluid, often with scope for promotion (Wessels and Pilz 2018). This training practice forms the basis for acquiring expert status, and it is common to find long-serving employees actually running operations. They are also capable of devising well thought-out solutions to problem situations, drawing on wide strategic experience as well as a practical and intuitive approach. To familiarise them as rapidly as possible with day-to-day routines, new workers go direct to a workstation of a project after their general induction to the company. The factory floor is the only learning environment: there is no cooperation with vocational schools. The manager of a mechanical engineering company explained:

"We don't try to structure anything. So, he will start working with one of the technicians in the purchase department. He will move around with him. He is like an additional hand. [...] We count on him. Wherever he is, he is one man available for doing work." (Interview I38)

All training takes place on the job. The requirements of companies are derived from intensive assembly-line processes focusing primarily on manual tasks, mostly in individual or small-scale manufacturing. Production in these companies is often project-based, and workers are responsible for individual manipulations but also have scope to make decisions. The companies involved are mostly small mechanical engineering businesses with up to 200 staff, so production staff can often be deployed in a range of functions. One difference from the other models is in the training of many production staff, which bears a certain similarity to the German approach.

\section{Description and Interpretation of the Findings}

As the findings of this study show, foreign subsidiaries of German manufacturing companies operate a range of initial and continuing training variants, some based on the dual model, some based on local training practice, and many adopting hybrid solutions. Figure 1 below provides a graphic overview, which depicts the findings in a simplified and highly aggregated form.

The illustration of these models represents a simplified aggregation of individual findings. For example, the need for specialists with complex training based on dualoriented approaches is restricted to a small proportion of the workforce in most cases, so dual-oriented approaches are the norm - the general training culture - in only a few of the companies considered (Pilz 2009). Practice in individual companies spans a wide range of initial and continuing training activities geared to the differing training needs of individual occupational groups.

Our data reveals a stable trend, however: the orientation to local training practice is the dominant model in all three countries, with German companies exclusively adopting this model or a significant number of companies using it for 


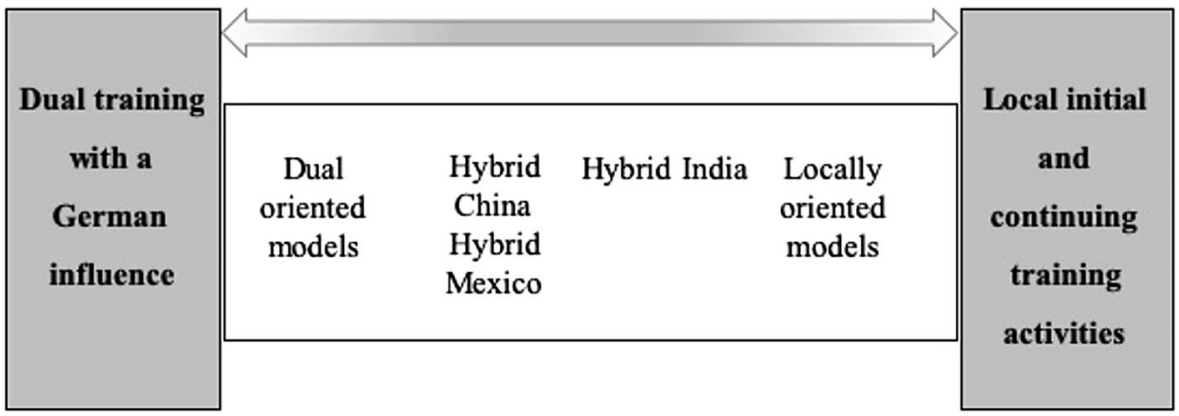

Fig. 1 Models on a continuum between German and local training practice (based on Wiemann 2020b, p. 296)

the majority of their employees. One reason is that routine activities make up most of their job for many production workers. Often, more complex training activities are open only to a small number of specialists, with components of the German dual model integrated. Production specifics and sectoral requirements have a major influence on companies' staffing needs, so the level of standardisation and production automation are relevant. Kumar and Suresh (2008) also argue that standardisation exerts a direct influence on the need for specialists: while Taylorite mass production (e.g. in vehicle and component manufacturing) breaks down working processes into small, simple stages, routine and knowledge-intensive small-scale production and project-based individual production requires more indepth understanding of production, for example the construction of specialist machinery or plant. Strongly Taylorite production concepts therefore require lower-level skills, while holistic production concepts and high-performance work systems (Appelbaum et al. 2000) require higher-level skills.

A further finding is the clear parallels between the three countries in relation to company size: in all three, global players often establish their own training centres and, with the support of the parent company, deploy substantial resources to align training closely to the German dual model. Most smaller multinationals do not have these resources and have to adapt to the local context. The HR manager of a machine manufacturer stressed that without cooperation partners and links with the local TVET system, it is largely impossible to offer robust training:

"Unfortunately, all the companies are on their own. In th[at] sense, there is not really an organised way between the companies or the government to achieve that training requirement or to enhance skills. It is left to the companies themselves. As a result, what happens is that bigger companies that have thousands of employees can afford training. They have the capacity to manage the infrastructure required, but others cannot." (Interview I7)

Alternatives are cooperation with German companies and the use of commercial external providers (such as private vocational schools), which offer many such arrangements.

A further central finding relates to the relationship alluded to in the Introduction between the parent company and its foreign subsidiary. This study found clear evidence 
of significant local autonomy for subsidiaries in the way they design their initial and continuing training activities and few links with the parent company in terms of organising training activities. There is therefore little evidence of German models at strategic level: rather, in many foreign subsidiaries, the design and operation of training makes no detailed reference to the German dual model. The manager of a Chinese training centre explained the demands placed on trainers:

"We are searching for teachers for a long time - for over half a year. First, they need skills. They need seven to ten years' experience in tooling. They should also know machining. The other thing is that they should have some experience with dual education. But this is very difficult. [...] We also see if they have work experience in German companies and know English." (Interview C31)

This illustrates the importance of the role of individuals in both promoting and hampering dual training in German companies' foreign locations (Gessler 2019).

The coordinator of global training activities at one multinational's headquarters also, however, stressed the autonomy local plants have:

"We start by showing them how we organise training here in Germany, and then it is up to the local manager to use that as he chooses. We want to be pulled, rather than to push." (Interview D4)

Overall, most countries orient their activities to local training models, with rather few global training strategies planned from Germany (Pilz and Li 2014). However, approaches based partially on the German dual training model are becoming more common, albeit mostly in locally-adapted forms. The study therefore confirms the assumption of a strong local influence.

The findings therefore also confirm the arguments in the literature that full transfer of an entire system is not possible (see Introduction): rather, the idea of the dual system (Gonon 2014) is transferred with its actual form adapted to local circumstances. In particular, our findings show that training must be worthwhile for companies and that this must be the focus of potential transfer activities. The training manager of an automotive component supplier explained:

"[...] There is another concept for the cost: how long is Production waiting for these new operators to be able to work on the front line? You know the operators have nothing to contribute to the company before they work on the front lines. The longer they stay in the classroom or the practice room, you know all the practice room finished materials or products cannot be delivered to the customers, the more cost to the company" (Interview C30)

Particularly in countries with no tradition of dual training, companies are sensitive to cost. The training company bears the loss when expensively-trained workers subsequently leave the company or are recruited by other employers (Mohrenweiser, Zwick and Backes-Gellner 2019; Muehlemann and Wolter 2011), and this is a risk in countries with very flexible labour markets. The HR manager of an automotive manufacturer explained: 
"Yes, [turnover] is very high. We see considerable instability in our workforce. We know that this can be attributed to a good supply of jobs. Employees come and try us out, stay two or three months, and then, if they don't like it here, they know they can get a job elsewhere. There is plenty of work, and it is hard to retain workers." (Interview M31)

However, many also emphasise that good post-apprenticeship development opportunities are crucial to keeping young former trainees loyal:

"We've trained them, they've spent three years with us, so they know the machines and everything. They are at a very high level when they finish their training, and plenty of other companies would like to recruit them, so we have to work hard to keep them." (Interview M70)

However, specific regional characteristics also need to be taken into consideration alongside country-specific differences. The selected regions are strongly industrial and have a high density of German and, in some cases, other international companies.

Important influences on the types of training include internal company characteristics that shape the mode of production and, hence, the specific need for trained staff. One example would be technology-intensive production that may generate a higher demand for trained specialists. Closely related to this are cost-benefit aspects that also determine long-term calculations and investment. These aspects are particularly evident in larger companies in this study and reflect the value of the individual subsidiary to the structure of the larger company or group. If its role is primarily to make production as cheap as possible by means of an 'extended workbench', then the company will be less willing to invest in complex training activities. If, on the other hand, a foreign location is seen as being autonomous and having potential for investment, then complex training is often seen as a worthwhile investment.

\section{Conclusions}

Our study documents very differentiated training practice within companies, although the findings must be set against limitations in the design. The findings on actual training practice and the influences on it cannot be generalised across or beyond regions. It can be assumed that further strategies and influences could also be identified, particularly in other countries. The companies in the sample are not representative with regard to factors such as production profile, company size and time established in the location. It is also evident that they represent highly aggregated findings on a continuum (see Fig. 1). For reasons of space, however, we are unable to consider the findings in a differentiated way that includes sub-types.

The study's findings nevertheless reflect those of Aring (2014), Gessler (2017) and Pilz and Li (2014) based on an individual company perspective. Our findings go a little further: complex analysis of a wide-ranging sample highlights differentiated training models that supersede individual country models and also reflect differing but parallel models within individual companies. This indicates that highly-aggregated country typologies of entire TVET systems (e.g. Pilz 2016a) cannot effectively portray the 
complex structures, steering mechanisms and design options involved in TVET and neglect important details. Involving small and medium-sized enterprises and 'smaller large companies' would expand the focus, enabling analysis of the opportunities and limitations on training design also in these company settings.

The findings demonstrate clearly that companies perceive and reflect local conditions to differing degrees. Local influences, such as weak links with vocational schools, low socio-cultural esteem for TVET and manufacturing employment and volatile labour markets, were described by company representatives as obstacles to the transfer of dual training approaches. However, these obstacles can be overcome by the design of in-company training, as India shows. A further example is the influence companies in China and Mexico exert over practical orientation of vocational schools. Companies are, therefore, a relevant point of access for transfer activities.

An important finding of the study is the diverse existence of training hybrids. These hybrids combine local and German aspects of training in a way that is necessary and feasible for the company.

On this basis, the study also shows that while companies are able to tackle the challenges of country-specific contexts, they do not always seek to do so. Differing needs result in different training practiced. One example is technology-intensive manufacturing, which can generate significant requirements for skilled specialists. Cost-benefit aspects are also important: independent and profitable foreign subsidiaries form part of the overall company structure, facilitating long-term calculations and investments. These aspects are particularly evident in larger companies. Although some companies pursue quality-optimised products, innovation potential and independent production and marketing strategies, others focus on being a cost-effective supplier for their parent company (Festing and Eidems 2011).

By contrast with the initial assumption, then, the external country-specific influence has proved not to be a virtually insuperable obstacle. Rather, it is clear that while the contextual framework exerts an influence on companies' training models, it can also be shaped by companies themselves. Companies may not be able to change the national framework but they are able to adapt individual aspects of it and make it possible to instigate dual approaches to TVET. This scope to shape training is influenced particularly by the conditions for production, which determine the requirement for trained specialists in subsidiaries and are subject to cost-benefit considerations. This study therefore also finds that internal company influences may be able to overcome countryspecific constraints but that companies do not always explore and exploit these. For example, in some German companies, task-specific and low-cost induction and forms of training are oriented to individual components of the German model and therefore produce new forms of locally specific training.

The many different facets of TVET illustrated in this article illustrate the difficulty of both analysing and transferring training systems in their entirety. It is also clear that system-level transfer aimed at transferring a system in its entirety - the model that has traditionally often applied to cross-border transfer - is unlikely to be successful in the long term. However, our findings show that there is potential for transfer at the level of individual stakeholders and of organisations: transfer at this level is able to combine elements from the vocational training system of the originating country as well as the recipient country in a way that is both flexible and demand-oriented. There is therefore a need for international comparative approaches to research that combine the 
perspective of individual participant, such as companies, with analysis of a wide range of stakeholders, reflecting the interaction between TVET and other parts of national training and employment systems.

Acknowledgments The project presented here was funded by the German Research Foundation (DFG) under the title "Global strategies and local forms of technical education and training in German multinational enterprises - A regional comparison in emerging economies" (PI 418/5-1). We thank our project partners Prof. Dr. Martina Fuchs and Judith Wiemann (University of Cologne) for many valuable insights and suggestions from an economic-geographical perspective.

Funding Information Open Access funding provided by Projekt DEAL.

Open Access This article is licensed under a Creative Commons Attribution 4.0 International License, which permits use, sharing, adaptation, distribution and reproduction in any medium or format, as long as you give appropriate credit to the original author(s) and the source, provide a link to the Creative Commons licence, and indicate if changes were made. The images or other third party material in this article are included in the article's Creative Commons licence, unless indicated otherwise in a credit line to the material. If material is not included in the article's Creative Commons licence and your intended use is not permitted by statutory regulation or exceeds the permitted use, you will need to obtain permission directly from the copyright holder. To view a copy of this licence, visit http://creativecommons.org/licenses/by/4.0/.

\section{References}

Allmendinger, J. (1989). Educational systems and labour market outcomes. European Sociological Review, 5(3), 231-250.

Appelbaum, E., Bailey, T., Berg, P., \& Kalleberg, A. L. (2000). Manufacturing advantage. Why highperformance work systems pay off. London: Ithaca.

Aring, M. (2014). Innovations in quality apprenticeships for high-skilled manufacturing jobs in the United States at BMW, Siemens, Volkswagen. Geneva: ILO.

Bartlett, C., \& Ghoshal, S. (1989). Managing across Borders. The transnational solution. Boston: Harvard Business School Press.

Billett, S. (2001). Learning in the workplace. Strategies for effective practice. Crows Nest: Allen \& Unwin.

Busemeyer, M. R., \& Trampusch, C. (2012). The comparative political economy of collective skill formation. In M. R. Busemeyer \& C. Trampusch (Eds.), The political economy of collective skill formation (pp. 338). Oxford: Oxford University Press. doi. https://doi.org/10.1093/acprof:oso/9780199599431.003.0001.

Davoine, É., \& Deitmer, L. (2020). German dual training through apprenticeships: An exportable model? In J.-L. Cerdin \& J.-M. Peretti (Eds.), The success of apprenticeships (pp. 133-142). London: Wiley.

Bundesbank, D. (2019). Statistics on the structure and activity of foreign affiliates of German investors. Frankfurt: Deutsche Bundesbank.

Dickmann, M., Müller-Carmen, M., \& Kelliher, C. (2008). Exploring standardisation and knowledge networking processes in transnational human resource management. Personnel Review, 38(1), 5-25. https://doi.org/10.1108/00483480910920688.

Dowling, P. J., Festing, M., \& Engle, A. D. (2008). International human resource management. Managing people in a multinational context (5th ed.). London: Cengage Learning.

Festing, M., \& Eidems, J. (2011). A process perspective on transnational HRM systems - a dynamic capability-based analysis. Human Resource Management Review, 21, 162(3), -173. https://doi. org/10.1016/j.hrmr.2011.02.002.

Festing, M., Eidems, J., \& Royer, S. (2007). Strategic issues and local constraints in transnational compensation strategies: An analysis of cultural, institutional and political influences. European Management Journal, 25(2), 118-131. https://doi.org/10.1016/j.emj.2007.01.001.

Gessler, M. (2017). Educational transfer as transformation: A case study about the emergence and implementation of dual apprenticeship structures in a German automotive transplant in the United States. Vocations and Learning, 10(1), 71-99. https://doi.org/10.1007/s12186-016-9161-8. 
Gessler, M. (2019). Promotoren der Innovation im transnationalen Berufsbildungstransfer: Eine Fallstudie. In M. Gessler, M. Fuchs, \& M. Pilz (Eds.), Konzepte und Wirkungen des Transfers Dualer Berufsausbildung (pp. 231-280). Wiesbaden: Springer VS. doi. https://doi.org/10.1007/978-3-65823185-9_7.

Gessler, M., Fuchs, M., \& Pilz, M. (Eds.). (2019). Konzepte und Wirkungen des Transfers Dualer Berufsausbildung. Wiesbaden: Springer VS. doi: https://doi.org/10.1007/978-3-658-23185-9.

Gonon, P. (2014). Development cooperation in the field of vocational education and training The dual system as a global role model? In M. Maurer \& P. Gonon (Eds.) The challenges of policy transfer in vocational skill development. National qualification frameworks and the dual model of vocational training in international cooperation (pp. 241-259). Bern: Peter Lang.

Hao, Y. (2012). The reform and modernization of vocational education and training in China. WZB discussion paper no. SP III 2012-304. Berlin: WZB.

Holmes, B. (1958). The problem approach in comparative education. Some methodological considerations. Comparative Education Review, 2(1), 3-8. https://doi.org/10.1086/444764.

Kuckartz, U. (2014). Qualitative text analysis: A guide to methods, practice and using software. London: Sage. doi. https://doi.org/10.4135/9781446288719.

Kumar, A. S., \& Suresh, N. (2008). Production and operations management. With skill development, Caselets and cases (2nd ed.). Neu Delhi: New Age International.

Lauder, H., Brown, P., \& Ashton, D. (2017). Theorizing skill formation in the global economy. In J. Buchanan et al. (Eds.) The Oxford Handbook of Skills and Training. Oxford: University Press online. doi: https://doi.org/10.1093/oxfordhb/9780199655366.013.17.

Lewis, T. (2007). The problem of cultural fit - what can we learn from borrowing the German dual system? Compare: A Journal of Comparative and International Education, 37(4), 463-477. https://doi. org/10.1080/03057920701366408.

Li, J., Wiemann, K., Shi, W., Wang, Y., \& Pilz, M. (2019). Vocational training in Chinese and German companies in China: A "home international" comparison. International Journal of Training and Development, 23(2), 153-168. https://doi.org/10.1111/ijtd.12151.

Meuser, M., \& Nagel, U. (2009). The expert interview and changes in knowledge production. In A. Bogner, B. Littig, \& W. Menz (Eds.), Interviewing experts. Research methods series (pp. 17-42). London: Palgrave Macmillan. doi. https://doi.org/10.1057/9780230244276_2.

Mohrenweiser, J., Zwick, T., \& Backes-Gellner, U. (2019). Poaching and firm-sponsored training. British Journal of Industrial Relations, 57(1), 143-181. https://doi.org/10.1111/bjir.12305.

Muehlemann, S., \& Wolter, S. C. (2011). Firm-sponsored training and poaching externalities in regional labor markets. Regional Science and Urban Economics, 41(6), 560-570. https://doi.org/10.1016/j. regsciurbeco.2011.04.003.

Pilz, M. (2009). Initial vocational training from a company perspective: A comparison of British and German in-house training cultures. Vocations and Learning, 2(1), 57-74. https://doi.org/10.1007/s12186-0089018-X.

Pilz, M. (2012). International comparative research into vocational training: Methods and approaches. In M. Pilz (Ed.), The future of vocational education and training in a changing world (pp. 561-588). Wiesbaden: Springer VS. https://doi.org/10.1007/978-3-531-18757-0.

Pilz, M. (2016a). Typologies in comparative vocational education: Existing models and a new approach. Vocations and Learning, 9(3), 295-314. https://doi.org/10.1007/s12186-016-9154-7.

Pilz, M. (2016b). Training patterns of German companies in India, China, Japan and the USA: What really works? International Journal for Research in Vocational Education and Training, 3(2), 66-87. https://doi.org/10.13152/IJRVET.3.2.1.

Pilz, M. (2016c). Training like at home or like the domestic competitors? -a study of German and Indian companies in India. In A. Yasin \& R. B. Shivagunde (Eds.), Emerging trends in technical and vocational education and training (TVET) (pp. 2-14). New Delhi: Lenin Media.

Pilz, M. (2017). Policy borrowing in vocational education and training (VET) - VET system typologies and the "6 P strategy" for transfer analysis. In M. Pilz (Ed.), Vocational education and training in times of economic crisis. Lessons from around the world (pp. 473-490). Springer. doi: Cham. https://doi. org/10.1007/978-3-319-47856-2.

Pilz, M., \& Li, J. (2014). Tracing Teutonic footprints in VET around the world? The skills development strategies of German companies in the USA, China and India. European Journal of Training and Development, 38(8), 745-763. https://doi.org/10.1108/EJTD-10-2013-0110.

Przeworski, A., \& Teune, H. (1970). The logic of comparative social inquiry. Comparative studies in behavioral science. New York: Wiley-Interscience. 
Ryan, P. (2012). Book review of The political economy of collective skill formation. Journal of Vocational Education and Training, 64(3), 381-385. Doi: https://doi.org/10.1080/13636820.2012.706438.

Seawright, J., \& Gerring, J. (2008). Case selection techniques in case study research: A menu of qualitative and quantitative options. Political Research Quarterly, 61(2), 294-308. https://doi.org/10.1177 /1065912907313077.

Stockmann, R., \& Silvestrini, S. (2012). Summary of the synthesis and meta-evaluation report. Technical and vocational training. Saarbrücken: GIZ.

Thelen, K. (2004). How institutions evolve: The political economy of skills in Germany, Britain, the United States and Japan. New York: Cambridge University Press.

Valiente, O., \& Scandurra, R. (2017). Challenges to the implementation of Dual Apprenticeships in OECD Countries: A Literature Review. In: M. Pilz (Ed.), Vocational Education and Training in Times of Economic Crisis. Lessons from around the World (technical and vocational education and training, Vol. 24, pp. 41-57). Cham: Springer. Doi: https://doi.org/10.1007/978-3-319-47856-2.

Wessels, A., \& Pilz, M. (2018). India. International Handbook of Vocational Education and Training, (issue 50, Vol. 24). P. Grollmann, D. Frommberger, U. Clement, T. Deißinger, U. Lauterbach, M. Pilz, \& G. Spöttl (Eds.), Bonn: BIBB. Retrieved from https://www.bibb. de/veroeffentlichungen/en/publication/download/9574

Wiemann, J., \& Fuchs, M. (2018). The export of Germany's "secret of success" dual technical VET: MNCs and multiscalar stakeholders changing the skill formation system in Mexico. Cambridge Journal of Regions, Economy and Society, 11(2), 373-386. https://doi.org/10.1093/cjres/rsy008.

Wiemann, K. (2018). Vocational teachers and in-company trainers in Mexico: Under-trained and under pressure. In S. McGrath, M. Mulder, J. Papier, \& R. Suart (Eds.), Handbook of vocational education and training: Developments in the changing world of work (pp. 1.717-1.731). Cham: Springer. doi. https://doi.org/10.1007/978-3-319-49789-1_37-1.

Wiemann, K. (2020a). Country study Mexico. International Handbook of Vocational Education and Training, Leverkusen: Barbara Budrich. Online.

Wiemann, K. (2020b). Qualifizierungspraxis deutscher Produktionsunternehmen in China, Indien und Mexiko. Eine Analyse der Übertragbarkeit dualer Ausbildungsansätze, Wiesbaden: Springer VS.

Wiemann, K., \& Pilz, M. (2020). Transfer research as an element of comparative vocational education and training: An example of factors influencing the transfer of dual training approaches of German companies in China, India and Mexico. In M. Pilz \& J. Li (Eds.), Comparative vocational education research: Enduring challenges and new ways forward (pp. 199-219). Wiesbaden: Springer VS.

Wolf, S. (2017). International Technical and Vocational Education and Training (TVET) Transfer ProjectTheoretical-Practical Experiences of Workplace Training with the Workforce in the Egyptian Construction Industry. In M. Pilz (Ed.), Vocational Education and Training in Times of Economic Crisis. Lessons from Around the World (technical and vocational education and training, Vol. 24, pp. 439-459). Cham: Springer. Doi: https://doi.org/10.1007/978-3-319-47856-2.

Zimmermann, K. F., Biavaschi, C., Eichhorst, W. Giulietti, C., Kendzia, M. J., Muravyev, A., Pieters, J., Rodríguez-Planas , N., \& Schmidl, R. (2013). Youth unemployment and vocational training. Foundations and trends in microeconomics, (volume 9, pp. 1-157). Doi: https://doi.org/10.1561/0700000058

Publisher's Note Springer Nature remains neutral with regard to jurisdictional claims in published maps and institutional affiliations.

Prof. Matthias Pilz is Full Professor of Economics and Business Education at the University of Cologne. He is Director of the German Research Center for Comparative Vocational Education and Training (G.R.E.A.T.). His major research areas include international comparative research into vocational education and training, transitions between training and employment, and teaching and learning.

Dr. Kristina Wiemann is research assistant within the Chair of Economics and Business Education at the University of Cologne. Her research interests include international comparative VET research and research concerning in company training and international training strategies. 